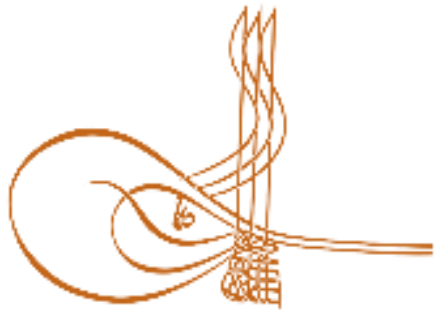

www.turkishstudies.net/social
Turkish Studies - Social Sciences

eISSN: $2667-5617$

Research Article / Araşttrma Makalesi

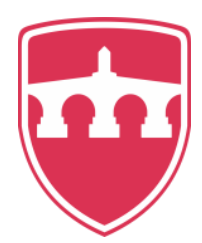

INTERNATIONAL

BALKAN

UNIVERSITY

Sponsored by IBU

\title{
X ve Y Kuşağı Tüketicilerin Nomofobik Eğilimlerinin Çevrimiçi Alışveriş Bağımlılığı ile Olan İlişkisinin Belirlenmesi*
}

\author{
Determining the Relationship Between Nomophonic Intentions of $X$ and $Y$ \\ Generation Consumers and Online Marketing
}

\author{
Funda Civek $^{* *}-$ Gürkan Ulusoy ${ }^{* * *}$
}

\begin{abstract}
Change is one of the most common concepts we encounter in our daily lives. The world has gone through great change processes. The most up-to-date technological element that has changed our world in recent years is undoubtedly the internet. In fact, the internet, which was originally thought of as a military/defense communication system, has undergone a change in its journey of development and has transformed every area it has spread. The dominant technology of our age, the internet, has taken the purchase action of individuals to virtual platforms. Mobile phones integrated with internet technology have become indispensable in our daily lives. Technology makaes the lives of individuals easier, but advancing technology has brought along addictions. Nomophobia has been the given to this negative situation caused by smartphone addiction. The aim of this study was to determine the relationship between $\mathrm{X}$ and $\mathrm{Y}$ generation consumers nomophobic tendencies and online shopping addiction. He has done research on nomophobia and online shopping addiction seperately in the literature. This study has original value in the literature in terms of the first study of the relationship between consumers fear of mobile phone and online purchasing decision. The study universe of the $\mathrm{X}$ and $\mathrm{Y}$ generation consumers. Field survey of the study was conducted with 394 consumers and face to face survey method was applied. Simple random sampling method was chosen to determine the sample of the study. The data collected with the questionnaire was analyzed using SPSS statistical software. The participants were categorized according to their nomophobic tendencies using Nomophobia Scale. $24,6 \%$ of the participants were found to be mild, $66 \%$ were moderate and 7,9\% were extremely mobile phone addicts. Significant differences were found in the hypotheses about the relationship between consumer's nomophobic tendencies and purchasing decisions.
\end{abstract}

\footnotetext{
* Bu makale Econder 1. Uluslararası İktisat, İşletme ve Sosyal Bilimler Kongresinde özet bildiri olarak sunulmuştur.

** Doktora Öğrencisi, Hitit Üniversitesi Sosyal Bilimler Enstitüsü.

PhD Student, Hitit University, Graduate School of Social Sciences

ORCID 0000-0002-8300-6402

ffunda.civek@gmail.com

*** Doktora Öğrencisi, Hitit Üniversitesi Sosyal Bilimler Enstitüsü

PhD Student, Hitit University, Graduate School of Social Sciences

ORCID 0000-0002-7516-9076

gurkan.ulusoy@windowslive.com
}

Cite as/ Atıf: Civek, F., Ulusoy, G. (2020). X ve Y kuşağı tüketicilerin nomofobik eğilimlerinin çevrimiçi alışveriş bağımlılı̆̆1 ile olan ilişkisinin belirlenmesi, Turkish Studies - Social, 15(1), 141-156. https://dx.doi.org/10.29228/TurkishStudies.40246

Received/Geliş: 20 December/Aralık 2019

Accepted/Kabul: 25 February/Şubat 2020

Copyright $(C)$ INTAC LTD, Turkey

Checked by plagiarism software

Published/Yayın: 29 February/Şubat 2020

CC BY-NC 4.0 
Structured Abstract: The spread of online communication has brought some convenience to our lives. Of course, every positive situation can bring negative results in pursuit. One of these results is nomophobia, the new disease of technology. No Mobile Phone Phobia is the fear of being deprived of a mobile phone. The use of mobile phones, which we can easily analyze many processes, has reached the degree of addiction; these devices have almost become a human limb.

Internet technology, which was considered as a communication tool for the defense industry more than half a century ago, has become the biggest technology of the age with its development over time. In addition, in addition to the development and change it has shown, it has transformed and transformed all the sectors and business areas it finds use in; has found new application areas. Especially in the process that started with the application area in the field of communication, the usage purposes of mobile devices have changed and almost all devices have been redesigned within the scope of internet technology. Mobile phones are among the tools most affected by this change and development. Mobile phones, which started to spread to the base in our country especially since the end of 1990 s, were initially a communication device, and nowadays, they have become pocket computers where almost every process can be easily performed. These powerful devices equipped with internet infrastructure are also known as smart phones.

Nomophobia is the biggest and perhaps the most unaware habit of the last period or a different discourse. This concept expresses the fear of being deprived of mobile devices which are more functional with internet technology and find more usage areas.

Along with the modern process, in a manner that varies according to the social structure and culture; consumption in societies has also changed. Consumption has not only focused on products and services, but has also become the head of the conditions that determine and show social identity and dignity. Thus; consumption awareness has become an economic phenomenon and turned into a social, psychological and cultural situation. Moreover, new generations born with this cultural consciousness have become more and more internalized and have used and continue to use the various opportunities provided by the consumer culture to create their own selves. In the past, shopping style, which is generally based on face to face and written method, has become increasingly electronic in our age. As a new distribution channel, shopping through the internet gives consumers the opportunity to shop and pay remotely. Without the need of consumers to go to the store for shopping; Online shopping, which provides the opportunity to purchase the products and services they need from their homes, workplaces, offers various possibilities and conveniences. As a result of these developments, the term online shopping has emerged as new marketing and sales methods and channels (Ersoy, 2016: 1).

Advances in information communication technologies have caused a change in "shopping", as in most areas of daily life, and "e-shopping" has occurred, where consumers can shop on electronic devices 24/7 without having to go to the store (Start, 2008: 113). Online shopping is defined as the stage of purchasing a product or service through the internet channel (Li and Zhang, 2002: 508).

When we look at the literature, it is seen that the concept is frequently examined in the field of educational sciences. This study is original in terms of being the first study to examine the concept of nomophobia on the basis of generations.

This study aims to determine the relationship between nomophobic tendencies of consumers of X and Y generation with online shopping addiction.

The universe of the research is all individuals living in Kastamonu and Çorum provinces and using smart phones. The study sample is 394 people who are selected by simple random sampling method and use smart phones. In this study, survey method was used as data collection method. The face-to-face questionnaire with a total of 394 participants consists of three sections and 37 questions.

One of the scales used in the survey; It is the Nomophobia Scale developed by Y1ldirım and Correia and adapted to Turkish in 2015 by Yıldırım, Sumuer, Adnan, Yıldırım. The other scale is the Compulsive Online Purchasing Scale of the Bergen Shopping Addiction Scale, adapted by Bozdağ and Alkar (2018). 5point Likert type scale was used in the mentioned scales.

The findings obtained in the study are as follows: $22.85 \%$ of the consumers participating in the study are women $(n=90)$ and $77.15 \%$ are men $(n=304)$. According to the birth years of the participants; Generation 
$\mathrm{X}$ is $9.64 \%(\mathrm{n}=38)$ and Generation $\mathrm{Y}$ is $88.3 \%(\mathrm{n}=356)$. While the rate of consumers whose income is less than $1,500 \mathrm{TL}$ is $61,4 \%(\mathrm{n}=242)$, the ratio of consumers with $6,000 \mathrm{TL}$ and above is $4,6 \%(\mathrm{n}=18)$.

Cronbach Alpha reliability analysis was applied to each scale group before the hypotheses were tested. Reliability analysis is used to determine the reliability levels of measurement elements such as test, survey and scale (Kalayc1, 2006: 403).

Two scales, namely nomophobia and online shopping addiction scale, were used in the research. The Cronbach Alpha Coefficient of the scale consisting of questions related to Nomophobia Scale was determined as 0.876 . The reliability of the nomophobia scale can be expressed as $87.6 \%$. Accordingly, it can be stated that the Nomophobia Scale is at the 'High Reliability' level according to the Alpha coefficient. Accordingly, it can be stated that the Nomophobia Scale is at the 'High Reliability' level according to the Alpha coefficient.

The findings obtained from the hypotheses determined within the scope, purpose and assumption of the research are as follows: According to the Anova test results for the conclusion of the H1 hypothesis, a difference of $\mathrm{p}<0.05$ significance level was determined. To conclude the $\mathrm{H} 2$ hypothesis, it was tested using MANOVA (Multivariate Analysis of Variance) - Multivariate Analysis of Variance. According to the results of the analysis, the hypothesis was rejected because it was $0.074>0.05$. To conclude the H3 hypothesis, it was tested using MANOVA (Multivariate Analysis of Variance) - Multivariate Analysis of Variance. According to the results of the analysis, the hypothesis was rejected because it was $0.346>0.05$.

According to the results obtained from the study, a significant relationship was determined between generations and nomophobic trends; No significant relationship could be detected between generations and online shopping addictions, and finally, no significant relationship could be detected between genders and online shopping addiction by generations. Considering the results of the acceptance, it can be stated that the frequency of the $\mathrm{Y}$ generation is high and the number of female participants in the third hypothesis will be effective.

In the literature studies reviewed, it was concluded that the nomofobic trends were high in most of the individuals in general. As a result of the concepts associated with Nomophobia, it is not possible for individuals to remain separate from their mobile phon Since the studies conducted are mostly related to educational sciences, this study has the characteristic of being unique value in terms of analyzing the literature on generations basises in the studies conducted.

In the future studies, the relationship between $\mathrm{Z}$ generation or education levels and the concept of nomophobia can be examined.

Keywords: Nomophobia, Online Shopping, Generations.

Öz: Değişim, günlük yaşantımızda en çok karşılaştığımız kavramların başında yer almaktadır. Dünyamız büyük değişim süreçlerinden geçmiştir. Son yıllarda dünyayı değiştiren en güncel teknolojik unsur hiç şüphesiz internettir. Öyle ki, başlangıçta askeri/savunma haberleşme sistemi olarak düşünülen internet, gelişim yolculuğu içerisinde önce kendisi bir değişim yaşamış ve sirayet ettiği her alanı değiştirip dönüştürmüştür. Çağımızın hakim teknolojisi olan internet, bireylerin satın alma aksiyonunu sanal platformlara taşımıştır. İnternet teknolojisi ile entegre olan cep telefonları, günlük yaşamımızın vazgeçilmezi haline gelmiştir. Teknoloji, bireylerin yaşamlarını kolaylaştırmaktadır, ancak ilerleyen teknoloji beraberinde bağımlılıkları da getirmiştir. Akıllı telefon bağımlılığının beraberinde getirmiş olduğu bu olumsuz duruma verilen isim nomofobi olmuştur. Bu çalışmanın amacı, X ve Y kuşağı tüketicilerin nomofobik eğilimlerinin çevrimiçi alışveriş bağımlılığı ile olan ilişkisinin belirlenmesidir. Literatürde ayrı ayrı nomofobi ve çevrimiçi alışveriş bağımlılığı ile ilgili araştırmalar yapılmıştır. Bu çalışma, Tüketicilerin cep telefonsuzluk korkusu ile çevrimiçi satın alma kararı arasındaki ilişkinin ilk kez çalışılması yönüyle literatürde özgün değer taşımaktadır. Araştırmanın çalışma evrenini X ve Y kuşağı tüketiciler oluşturmuştur. Çalışmanın alan araştırması 394 tüketici ile gerçekleştirilmiş ve yüz yüze anket metodu uygulanmıştır. Çalışmanın örneklemini belirlemek için basit tesadüfi örnekleme metodu seçilmiştir. Anket formu ile toplanan veriler SPSS istatistik paket programı kullanılarak çözümleme yapılmıştır. Çalışmaya katılan bireyler Nomofobi Ölçeği kullanılarak nomofobik eğilimlerine göre kategorize edilmiştir. Katılımcıların \%24,6's1 hafif düzeyde, \%66's1 orta düzeyde ve \%7,9’luk bölümü ise aşırı düzeyde cep telefonu bağımlısı olarak belirlenmiştir. Tüketicilerin Nomofobik eğilimleri ile satın alma kararları arasında ilişkiye dair kurulan hipotezlerde anlamlı farklılıklar tespit edilmiştir.

www.turkishstudies.net/social 
Anahtar Kelimeler: Nomofobi, Çevrimiçi Alışveriş, Kuşaklar

\section{Giris}

Çevrimiçi iletişimin yaygınlaşması hayatımıza bazı kolaylıkları getirmiştir. Tabi her olumlu durum peşinde olumsuz sonuçları da getirebilmektedir. Bu sonuçlardan bir tanesi de teknolojinin yeni hastalığı olan nomofobidir. No Mobile Phone Phobia, cep telefonundan yoksun kalma korkusudur. Pek çok işlemi kolaylıkla çözümleyebildiğimiz bir cihaz olan cep telefonu kullanımı bağımlılık derecesine ulaşmış; bu cihazlar neredeyse bir insan uzvu haline gelmiştir.

Nomofobi, son dönemin en büyük ve belki de en farkında olunmayan alışkanlık ya da farklı bir söylem hastalığıdır. Bu kavram internet teknolojisi ile birlikte daha fazla fonksiyonel olan ve kendisine daha fazla kullanım alanı bulan mobil cihazlardan yoksun kalma korkusunu ifade etmektedir. Literatüre bakıldığında genellikle eğitim bilimleri alanında kavramın sıkça irdelendiği görülmektedir. Bu çalışma nomofobi kavramını kuşaklar bazında inceleyen ilk çalışma olması yönüyle özgün değer taşımaktadır.

$\mathrm{Bu}$ çalışma $\mathrm{X}$ ve $\mathrm{Y}$ kuşağı tüketicilerin nomofobik eğilimlerinin çevrimiçi alışveriş bağımlılığı ile olan ilişkisinin belirlenmesini amaçlamaktadır. Bu amaç doğrultusunda çalışmada ilk olarak kavramla ilişkili olan literatür taraması yapıldıktan sonra, nomofobi, kuşaklar ve online alışveriş kavramları teorik olarak açıklanarak devamında $X$ ve $Y$ kuşağı tüketicileri üzerinde uygulanan anket sonuçları ve anket sonuçlarından elde edilen saptamalara yer verilmiştir.

\section{Literatür Taraması}

Tavolacci v.d. (2015) tarafından yapılan araștırmada nomofobi ve çevresel değişkenler arasında bir ilişkinin olup olmadığı araştırılmıştır. 760 kişi ile yapılan bu çalışmanın sonuçlarına göre; üniversite talebelerinin nomofobi seviyeleri ile cinsiyet, günlük ileti kullanma sayıları ve telefon görüşmesi yaptıkları süreler arasında anlamlı fark olduğuna yönelik hipotezler kabul edilmiştir.

Lepp vd. (2016) tarafından yapılan araştırmada, cep telefonu kullanana üniversite öğrencilerinin hangi amaç ile kullandıkları ve nomofobik durumlarının aile ve yaşıtlarına bağlanma biçimleri incelenmiştir. Çalışma 493 üniversite öğrencisi yapılmış ve anket metodu kullanılmıştır. İlgili çalışmanın sonuçlarına göre; cep telefonunun sorunlu kullanımı ile aile ve yaşıtlara angaje olma arasında negatif yönlü bir bağlantı tespit edilmiştir. Erkek üniversite öğrencilerinde cep telefonu kullanımı fazlalaştıkça anne-baba ve yaşıtlara olan itimat hissi karşılıklı olarak eksilmiştir.

Erdem vd. (2016) tarafindan yapılan çalışma Malatya ili İsmet İnönü Üniversitesi, İktisadi ve İdari Bilimler Fakültesi'nde tahsil gören üçüncü ve dördüncü sınıf öğrencisi olan 312 kişi ile gerçekleştirilmiştir. İlgili çalışmada öğrencilerin nomofobik eğilimleri ile akademik başarı düzeyleri arasındaki ilişkinin olup olmadığı araştırılmıştır. Çalışmanın sonuçlarına göre araştırmaya katılan bireylerin büyük bölümünün nomofobik eğilimlere sahip olduğu ve günde en az 6 saat boyunca cep telefonu ile meşgul oldukları sonucu elde edilmiştir.

Gezgin (2017) tarafından yapılan çalışmada mobil internet kullanım durumlarının üniversite öğrencilerinin nomofobi düzeyleri üzerine etkisinin keşfedilmesi amaçlanmıştır. 429 kadın ve 216 erkek üniversite öğrencisi üzerinde yapılan araştırmanın sonuçlarına göre gün içerisinde cep telefonunu daha s1k kontrol, üniversite öğrencilerinin nomofobi düzelerinin diğerlerine nispeten daha etkili olduğu saptanmıştır. Ayrıca ehil olunan mobil internet süresi, günlük internet kullanımı süresi ve mobil hat internet kullanımı kotası gibi değişkenler üniversite öğrencilerinin nomofobi düzeylerini doğrudan etkilemektedir. 
Yıldırım ve Kişioğlu (2018), Nomofobi kavramını ilintili kavramlar olan netlessfobi (internetsiz kalma korkusu) ve FoMO (gelişmeleri kaçırma korkusu) ile birlikte incelemiştir. Nmofobi ve söz konusu diğer kavramları teknolojinin getirdiği yeni hastalıklar olarak incelemiş ve fiziksel ve psikolojik etkilerini kavramsal olarak ele almıştır.

Sırakaya (2018) tarafından yapılan çalışmada ön lisans düzeyinde öğrenim gören üniversite öğrencilerinin nomofobi düzeyleri akıllı telefon kulanım düzeylerine göre incelenmişir. 439 ön lisans öğrencisi ile yapılan çalışmanın sonuçlarına göre; sosyal ağlara bağlanmak ve alışveriş yapmak maksadıyla android telefonun kullanılması nomofobi seviyesini etkilerken öteki amaçlar ile telefon kullanılması nomofobi düzeyini etkilemediği sonucuna ulaşılmıştır.

Yıldırım vd. (2016) tarafindan yapılan araştırmada üniversite öğrencilerinin nomofobi düzeyleri araştırılmıştır. Çalışmaya 537 üniversite öğrencisi katılmış olup katılımcıların \%42,6’lık bölümünün nomofobik davranışlarının olduğu sonucuna ulaşılmıştır. Buna göre nomofobik olduğu belirlenen katılımcıların en büyük korkularının cep telefonlarından uzak kalmaları ve iletişime geçmekte problem yaşamaları ihtimalleri sonucuna ulaşılmıştır.

Işık ve Kaptangil (2018) tarafindan yapılan araştırmada üniversite öğrencilerinin cep telefonu kullanımı düzeyleri ile sosyal medya kullanım düzeyleri arasındaki ilişki araştırılmıştır. Bitlis Eren Üniversitesi öğrencisi olan 343 kişi ile yüz yüze anket yöntemiyle ve basit tesadüfi metod ile yapılan çalışmada cep telefonu bağımlılığı ve sosyal medya bağımlılığı arasındaki ilişkinin pozitif yönlü olduğu tespit edilmiştir.

\section{Kavramsal Çerçeve}

\subsection{Nomofobi}

Yarım asırdan fazla bir süre önce savunma sanayi için haberleşme aracı olarak düşünülen internet teknolojisi, zaman içinde gösterdiği gelişim ile çağın en büyük teknolojisi haline gelmiştir. Öyle ki kendi gösterdiği gelişim ve değişimin yanı sıra kullanım alanı bulduğu sektörlerin ve iş alanlarının tamamını değiştirip dönüştürmüş̧; yeni uygulama alanları bulmuştur. Özellikle iletişim alanında uygulama alanı bulması ile başlayan süreçte mobil cihazların kullanım amaçları değişmiş, hemen hemen tüm cihazlar internet teknolojisi kapsamında yeniden tasarlanmıștır. Cep telefonları da bu değişim ve gelişimden en çok etkilenen araçların arasında yer almıştır. Ülkemizde özellikle 1990'l y ylların sonundan itibaren tabana yayılmaya başlayan mobil telefonlar başlangıçta bir haberleșme cihazı iken günümüzde hemen her işlemin kolaylıkla gerçekleștirilebildiği cep bilgisayarları haline gelmiştir. İnternet altyapısı ile donatılan bu güçlü cihazlar smart (akıllı) telefon olarak da anılmaktadır.

TÜIKK verilerine göre, Türkiye'de bulunan hanelerde cep telefonu / akıllı telefon kullanım oranı 2004 yılında \%53,7 iken 2018 yılı itibariyle bu oran \%98,7'ye yükselmiştir (Hanelerde bilişim teknolojileri bulunma oran1, 2004-2018, 2019). Yine TÜIK'in 'Sabit Telefon, Cep Telefonu ve İnternet Abone Sayısı' başlıklı araştırmasının sonuçlarına göre, Cep telefonu abone sayısı 2018 yılı Eylül ayı itibariyle 80.637.671'e; internet abone sayısı ise 73.789 .734 kişiye ulaşmıştır (TÜíK, 2019). Söz konusu verilerden de anlaşılacağı üzere, çağın teknolojisi mobil cihazlar üzerinden ilerlemekte ve bu teknoloji bireyler tarafından yüksek oranda kabul görmektedir. Hayatımızın bütününe sirayet eden mobil telefon teknolojisinin kullanımı her geçen gün artmakta, bu yoğun kullanım ise bazı istenmeyen alışkanlıklar, hastalıklar ya da fobilere neden olabilmektedir. Nomofobi de bağımlılık ya da problemli kullanım oluşturacak davranışsal fobilerinden biridir. Nomofobi kavramına geçmeden önce, 'Fobi' kavramına değinmek faydalı olacaktır.

Fobi sözcüğü için Türk Dil Kurumu tarafindan yapılan tanımlama şu şekildedir: 2019).

"Belirli nesneler veya durumlar karşısında duyulan olağan dışı güçlü korku, yılgı" (TDK, 
Fobi, gerçek bir tehlikenin var olmadığ 1 durumlarda meydana gelen ve ortaya çıkma sebebinin tam olarak bilinmediği korkulardır (Yörükoğlu, 1990: 236). Fobi, nesne veya herhangi bir duruma karşı duyumlanan ve hissedilen rasyonel temeli olmayan aşırı korku halidir (Ertan, 2019: 41).

Fobiler, bir tür kaygı hali, kaygılanma durumudur. Fobi kavramı ilk kez 1700'lü yıllardaki Locke tarafından kullanılmıştır (Gençtan, 2015:175). Nomofobi ise oldukça yeni bir kavram (Ertan, 2019: 60), olmasının yanı sıra henüz farkında olunmayan fobiler arasındadır. Dilimize İngilizce'deki 'nomophobia' kavramından girerek karşıllk bulan nomofobi, İngiliz dilindeki 'No Mobile Phone Phobia' kelime setinden türetilen 'Nomophobia' kelimesinin karşılı̆̆ıdır. Kavram ilk defa 2008'de, İngiltere'deki çalışma ile literatüre girmiştir (Yıldırım ve Correia, 2015: 31). Nomofobi kavramına ismini veren ise Connectiut Üniversitesi araştırmacılarından David Greenfield olmuştur (Öz, 2018: $11)$.

Nomofobi; bazı insanların telefonlarına erişemedikleri durumda duydukları kaygı, endişe ve işlerini tamamlamak, bilgiye ulaşmak ve kişiler ile iletişimde kalma konusunda telefona bağımlı olma derecesi şeklinde tanımlamıştır (Scientific American, 2015). 2008 yılında İngiltere Posta İdaresi tarafından nomofobi ile ilgili bir araştırma yapılmıştır (Turen, Erdem ve Kalkın, 2017: 4). Akıllı telefon ile çok vakit geçirmek, pilinin bitmesinden endişelenmek, kaybetmek, kapsama alanı dışında kalmak, bakiyenin bitmesi, cep telefonuna mesaj ya da arama gelip gelmediğini sık sık kontrol etmek, tüm gün telefonunu açık tutmak ve telefon ile uyumak, akıllı telefon sahibi olmak için büyük borç ve masrafa girmeye razı olmak ile yüz yüze iletişimi sınırlı tutup daima yeni teknolojiler ile iletişim kurmak bazı özelliklerindendir (Bragazzi ve Del Puente'den akt.; Karatay, 2018: 4). Literatürde nomofobi ile birbirine benzeyen ancak aralarında küçük nüanslar bulunan bazı kavramlar da bulunmaktadır. Bunlar netlessfobi yani internetsiz kalma korkusu ile FoMO yani gelişmeleri kaçırma korkusudur. Bireylerin psikolojisinin bir türünü yansıtan FoMO (Song vd., 2017: 734) bireyin özellikle sosyal medya gibi alanlarda başkalarının kendisinden daha tatmin edici deneyimler yaşadığ 1 düşüncesi nedeniyle sürekli olarak çevrimiçi kalması yönünde güçlü bir istek duyması olarak ifade edilebilecektir (Alt, 2015: 111). Dilimize internetsiz kalma korkusu şeklinde çevrilen Netlessfobi, internet bağımlılığı neticesinde ortaya çıkmış olan oldukça yeni sayılabilecek bir kavramdır (Akman ve Işık, 2018: 23). Sosyal ağların yaygınlaşması ve günlük yaşantımızın önemli bir parçası haline gelmesi internetin önemini daha da artırmıştır. Bu nedenle bireyler internetsiz kalamama veya internetsiz bir ortamda bulunamamaya dair güçlü bir itici güç tarafindan kuşatılmaktadır (Güney, 2017: 211). Ancak sadece internetten yoksun kalmama dürtüsü netlessfobi olarak ifade edilememektedir. Netlessfobiden tam olarak söz edilebilmesi için bireylerin internetsiz kaldıkları durumlarda büyük sıkıntılar duyması, fiziksel ve ruhsal tepkimelerde bulunmas1 gerekmektedir (Öztürk, 2015: 634).

\subsection{Kuşaklar ve Alışveriş Alışkanlıkları}

Kuşak terimi tarihi süreç içerisinde incelendiğinde bu terimin Antik Yunan'a ve ayrıca eski Mısır medeniyetine dek gittiği görülmektedir(Mercan, 2016: 61). Bilimsel araştırmalar ise Auguste Comte öncülügünde 1830-1840 yılları arasında başlamıştır. Comte (1974), kuşak terimini birbirleriyle aynı ya da yakın periyotlarda dünyaya gelen kişilerin benzer spesiyalitelere ehil olmasına angaje etmiştir (Demirkaya ve diğ., 2015: 187). Genel bir ifade ile kuşak terimi, anne, baba ve çocukların doğumları arasındaki yaklaşık dönemi açıklamaktadır. Bu biyolojik açıklamaya göre her bir bin y1llık periyota 20-25 y1l aralıklarla bir jenerasyon girmektedir (Mercan, 2016: 61).

Kuşak kavramına Türk Dil Kurumu tararfından yapılan tanımlama ise şu şekildedir:

"Yaklaşık olarak aynı yıllarda doğmuş, aynı çağın şartlarını, dolayısıyla birbirine benzer sıkıntıları, kaderleri paylaşmış, benzer ödevlerle yükümlü olmuş kişilerin topluluğu" (TDK, 2020). 
Kuşakların sınıflandırması genel olarak yapılan çalışmalarda doğum tarihine göre; sessiz kuşak (1925-1945), baby boomers (1946-1964), X kuşağı (1965-1979), Y kuşağı (1980-1999) ve Z kuşağı (2000 ve sonrası) ifade edilmektedirler (Başgöze \& Bayar, 2015; Mücevher, 2015; Ordun, 2015; Yüksekbilgili, 2013). Fakat yapılan güncel çalışmalarda alfa kuşağ1 (2012 ve sonrası) eklenmiştir (Danışman \& Gündüz, 2018:709).

Tablo 1: Kuşakların Sınıflandırılması

\begin{tabular}{|c|c|c|}
\hline Kuşak & Doğum Yılı & Özellikleri \\
\hline $\begin{array}{l}\text { Sessiz } \\
\text { (Geleneksel) } \\
\text { Kuşak }\end{array}$ & $1925-1945$ & $\begin{array}{l}\text { - Uyumlu/Kanaatkar/Çalışkan/Tutkulu/Otoriteye Sadık } \\
\text { - Teknolojik ilerlemelerin çok fazla gözlenemediği aralık } \\
\text { - Savaş ve fakirlik gördüğünden dolayı başarılı ve güçlü kalabilmek } \\
\text { için hırs yapmıs bir jenerasyon }\end{array}$ \\
\hline $\begin{array}{l}\text { Baby } \\
\text { Boomers }\end{array}$ & 1946-1964 & $\begin{array}{lll}\text { - } & \text { Otoriteye bağlı/kanaatkar/Ben } \\
\text { odakl1/Kuralcı/Çalışkan/Sadık } & \text { merkeziyetçi/Başarı } \\
\text { - } & \text { Teknolojik ilerlemelere ahenk sağlayamamış } \\
\text { - Savaş sonrası doğum oranlarının artış gösterdiği bir dönem } & \\
\end{array}$ \\
\hline $\mathrm{X}$ kuşağ & $1965-1979$ & $\begin{array}{lllll}\text { - } & \text { Şüpheci/Duyarlı/Otoriteye bağlı / Mücadeyi } & \text { seven/ } \\
& \text { Kanaatkar/Sabırsız/Iş odaklı } \\
\text { - } & \text { Teknolojik ilerlemelere ahenk sağlamaya çalışan } & \\
\text { - Maddiyatın ön planda olan bir jenerasyon } & & \\
\end{array}$ \\
\hline Y Kuşağ & 1980-1999 & $\begin{array}{ll}\text { - } & \text { Girişimci/Otoriteye karş1 } \\
& \text { sergileyen/Gerçekçi/Şeffaf } \\
\text { - } & \text { Hayattaki çoğu şey için teknoloji onlar için temel araç ve sembol } \\
\text { - } & \text { Diğerlerinin fikirleri ve düşünceleri önemli, ekip ruhu ön planda olan } \\
& \text { bir jenerasyon }\end{array}$ \\
\hline Z Kuşağ1 & $\begin{array}{l}2000 \\
\text { sonras1 }\end{array}$ & $\begin{array}{l}\text { - Tüketici/ Tatminsiz/Sonuç odaklı/Iletişime açı/Kreatif düşünen/ } \\
\text { - Yeniliklere açık } \\
\text { - Teknoloji adeta uzuv niteliğinde } \\
\text { - Bireyselcilik ve yalnızcılık ön planda olan bir jenerasyon }\end{array}$ \\
\hline
\end{tabular}

Kaynak:https://alternatifbankkariyer.com/2014/07/17/sessiz-kusak-baby-boomers-X-y-zkusaklarinagenel-bakis/ Erişim Tarihi: 19.01.2020.

Modern süreçle birlikte, kültüre ve sosyal konstrüksiyona göre değişim sergileyen bir biçimde; topluluklardaki tüketen olgusu da değişime uğradı. Tüketim yalnızca ürün ve hizmete yönelik olmaktan çıkıp sosyal kimliği, saygınlığı açıklayan ve anlatan şartların da yön göstereni halini aldı. Böylece; tüketme bilinci, iktisadi bir durum olmanın yanında, kültürel, ruhsal ve toplumsal bir duruma dönüştü. İlaveten, bu kültür bilinci ile dünyaya gelen yeni kuşaklar, bunu git gide fazlaca özümsedi ve tüketim kültürünün sağlamış olduğu türlü firsatları kendi benliklerini meydana getirmek için harcadı ve harcamaya da devam ediyor. Geçmişte genel olarak yüz yüze ve yazılı yönteme dayanan alışveriş biçimi çağımızda git gide çoğalan bir şekilde elektronik duruma dönüşmüştür. İnternet aracılığıyla alışveriş tüketicilere konum değiştirmeden alışveriş ve ödeme avantajı sağlmaktadır. Tüketicilere fiziki mekana gitmeye gerek kalmadan bulunduları yerden ihtiyaç duydukları her anda ürün ve hizmet satın almalarına olanak sağlayan çevrimiçi alışveriş türlü olanaklar ve kolaylıklar sağlamaktadır. Bu gelişmeler nezdinde, yeni pazarlama ve satış metotları ve kanalları olarak çevrimiçi alışveriş terimi meydana gelimiştir (Ersoy, 2016: 1).

\section{3. Çevrimiçi Alışveriş}

Ticaret kavramı, bireylerin mal değiş tokuşu ile başlayıp bir değişim aracı olan ekmek, altın, fasulye, inci gibi malların kullanımıyla devam etmiştir. Zaman içerisinde bireylerin sattıkları mal 
karşıllğıında herhangi bir mal almak istememeleri alışverişin önünün kesilmesine sebep olmuştur. Ama paranın buluşundan sonra değişim aracı olarak para kullanılmaya başlanmıştır.

Elektronik Ticaret, satıcı ile müşterinin yüz yüze görüşmeden üretim, lansman, satım, sigorta, dağıtım ve tediye prosedürleri internet vasıtasıyla gerçekleştirilen ve ticareti kolay hale getiren bir yeniliktir. Elektronik ticaret araştırmaları Türkiye'de ilk kez 1998'de Bilim ve Teknoloji Yüksek Kurulu'nun (BTYK) düzenlediği bir toplantı ile ortaya çıkmıştır. Elektronik ticaret oluşumunun gelişmesinde etkili olan birden çok etmen vardır. Bunlar; internetin yaygınlığı, ödeme alternatifleri, elektronik ticaret araçlarının sayısı, taşıma işlemlerindeki gelişme ve en önemlisi nüfusun hacmi gibi konular önemli faktörler arasında bulunmaktadır (Yaman ve diğ., 2018: 143).

Elektronik ticaret oluşmadan evvel tradisyonel komünikasyon araçları kullanılarak veya yüz yüze uygulanan alışılmış yöntemler vasıtasıyla ticaret gerçekleştirilmiştir. Kitle komünikasyon ekipmanlarının ilerlemesi ve globalleşmeyle birlikte dünyanın her yerinde yayılması, bu ilerlemenin tesirini göstermesiyle kârın kapsamı da farklılaşmış ve elektronik ticaret olarak isimlendirilen yepyeni ticaret biçimine geçilmiştir (Yılmaz \& Uzunçelebi, 2015: 23). Genel anlamda e-ticaret kavramı, dokümanlarda sanal alışveriş, çevrimiçi alışveriş, online alışveriş, e-alışveriş, web tabanlı alışveriş, network alışveriş, internetten alışveriş gibi kavramlarla yakın manalı olarak değerlendirilmektedir (Akyüz, 2017: 4).

Günümüzde teknolojik alandaki hızlı farklılaşmalar ve internetin yaygınlık kazanarak yaşamımıza entegre olması ile beraber çoğu alanda olduğu gibi perakendecilik alanında da yenilikler ve ilerlemeler görülmektedir. Yeni bir pazarlama aracısı olarak gösterilen internet, tüketicilere farklı bir alışveriş konsepti platformu oluşturmakta, enerji harcamadan fiziki ortamlarda bulunma zorunluluğu olmadan, hatta mukayese yaparak ve farklı bireylerle istişare yapmak ve fikir alışverişinde bulunma gibi üstünlüklerden de yararlanarak satın alma problemini çözüme kavuşturma firsatı sağlamaktadır (Enginkaya, 2006: 10).

Online alışveriş fursatı sunan internet ortamları için önceden bilgisayar ihtiyacı duyulurken, çağımızda tabletler, akıllı telefonlar ve akıllı televizyonlar gibi güncel teknolojik aygitlarla da bu ürünlere erişmek mümkün hale gelmiştir. İnternetin günlük yaşama olan yansımaları, bugüne dek geleneksel metotlarla işleyen alışverişin de kendine uyumlu olarak değişimini bir anlamda zorunlu hale getirdiği söylenebilir. Teknolojik değişimlere paralel olarak "İnternet Üzerinden Alışveriş" kavramının gündeme geldiği ifade edilebilir (Akyüz, 2017: 7).

Bilgi iletişim teknolojilerindeki ilerlemeler günlük yaşamın çoğu alanında olduğu gibi "alışveriş" te de bir değişime sebep olmuş ve tüketicilerin mağazaya gitmesine gerek kalmadan elektronik aygıtlar üzerinden, 7 gün 24 saat alışveriş yapabildiği "e-alışveriş" oluşmuştur (Başlama, 2008:113). Çevrimiçi alışveriş, internet kanalı vasıtasıyla ürün veya hizmet satın alma aşaması olarak tanımlanmaktadır (Li ve Zhang, 2002: 508).

Globalleşmenin artmasıyla birlikte internet teknolojisindeki ilerlemelerde işletmelerin farklı tüketicilerle olan etkileşimini de artırmıştır. Çevrimiçi alışveriş sadece bir mouse yardımıyla işlemin tamamlanması bakımından zamandan tasarruf ve kolaylık sağlamasından dolayı tüketicilere de önemli bir yarar sağlamıştır. Güvenlik endişelerine rağmen online alışveriş yaygınlık kazanmıştır. $\mathrm{Bu}$ durum, bireysel elektronik aygitlar, internet abonelikleri vb. durumlar neticesinde kisaca internet bağlantısının olduğu her yerde insanlar vasıtasıyla sayının gitgide artış göstermesinden kaynaklanmaktadır (Kurnia ve Chien,2003: 219).

İnternet kullanım oranları tüm dünyada arttığı gibi Türkiye'de de artış göstermektedir. 2019 y1lı Ağustos ayında gerçekleştirilen Hane Halkı Bilişim Teknolojileri kullanım araştırması sonuçlarına göre hanelerin \%88,3'ü evden internete erişim imkânına sahiptir. İnternet üzerinden alışveriş yapma oranı 2018 yılı Nisan ve 2019 yılı Mart ayını kapsayan dönemde \%34,1 olmuştur. 
$\mathrm{Bu}$ oran cinsiyete göre dağ 1 lımda ise kadınlarda $\% 29,9$ iken erkeklerde bu oran $\% 38,3$ şeklindedir. Son olarak da internet kullanan bireylerin oranı da \%75,3 oranına ulaşmıştır (TÜİK, 2019).

\section{Araştırmanın Yöntemi}

\subsection{Araştırmanın Amacı, Kapsamı ve Sınırlılıkları}

Araştırmanın gayesi, $\mathrm{X}$ ve $\mathrm{Y}$ kuşağı tüketicilerin nomofobik eğilimlerinin çevrimiçi alışveriş bağımlılığı ile olan ilişkisinin belirlenmesidir. Çalışmanın ana kütlesini $X$ ve $Y$ kuşağı tüketiciler oluşturmuştur. Çalışmada yalnızca $X$ ve $Y$ kuşağı kapsamına giren bireyler ile çalışılması ve yalnızca akıllı cep telefonu kullanıcıları ile çalışma yapılacak olması çalışmanın kısıt ve sınırlılıkları arasında ifade edilebilecektir.

\section{2. Örnekleme Süreci ve Veri Toplama Yöntemi}

Araştırmanın evreni Kastamonu ve Çorum illerinde yaşayan ve akıllı cep telefonu kullanan kişilerin tamamıdır. Araştırma örneklemi ise basit tesadüfi örneklem metoduyla seçilen ve akıllı cep telefonu kullanan 394 kişidir. Bu araştırmada veri toplama metodu olarak anket yöntemi seçilmiştir. Toplam 394 katılımcı ile yüz yüze gerçekleştirilen anket üç bölüm ve 37 sorudan oluşmaktadır. Çalışmanın demografik bilgiler bölümü dışında iki ölçek kullanılmıştır. Bu ölçeklerin ilki Yıldırım ve Correia tarafından geliştirilmiş ve Yıldırım, Sumuer, Adnan, Yıldırım tarafından 2015 yılında Türkçeye uyarlanmış olan Nomofobi Ölçeği'dir. Diğer ölçek ise Bozdağ ve Alkar (2018) tarafindan uyarlanan Bergen Alışveriş Bağımlılığı Ölçeği’nin Kompülsif Çevrimiçi Satın Alma Ölçeği'dir. Söz konusu ölçeklerde 5'li Likert tipi ölçek kullanılmıştır.

\subsection{Araştırmanın Hipotezleri}

$\mathrm{Bu}$ çalışma $\mathrm{X}$ ve $\mathrm{Y}$ kuşağı tüketicilerin nomofobik eğilim düzeyleri ile çevrimiçi satın alma davranışları arasındaki ilişkiyi belirlemeyi amaçlamaktadır. Bu kapsamda üç temel hipotez geliştirilmiş ve bu hipotezler çeşitli istatistiki yöntemler kullanılarak ve SPSS istatistik paket programında test edilmiştir.

$\mathrm{H}_{1}$ : X ve $\mathrm{Y}$ kuşağı tüketiciler ile nomofobik eğilim düzeyleri arasında fark vardır.

$\mathrm{H}_{2}$ : X ve $\mathrm{Y}$ kuşağ arasında ilişki vardır. vardir

$\mathrm{H}_{3}: \mathrm{X}$ ve $\mathrm{Y}$ kuşağı tüketicilerin cinsiyetleri ile nomofobik eğilim düzeyleri arasında ilişki

\subsection{Araştırmanın Bulguları}

\subsubsection{Sosyo-Demografik Özellikler}

Tablo 2'de gösterildiği üzere, çalışmaya katılan tüketicilerin \%22,85'i kadın, \%77,15'lik bölümü ise erkektir. Katılımcıların doğum yıllarına göre; \%9,64'ü X kuşağı, \%88,3'ü Y kuşağıdır. Geliri 1.500 TL'den az olan tüketicilerin oranı $\% 61,4$ iken 6.000 TL ve üzeri olan tüketicilerin oran $\% 4,6$ olarak tespit edilmiştir. 
Tablo 2: Katılımcıların Demografik Özellikleri

\begin{tabular}{|c|c|c|c|c|c|c|c|}
\hline & Özellikler & Sayı & $(\%)$ & & Özellikler & Sayı & $(\%)$ \\
\hline \multirow{4}{*}{ 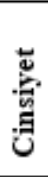 } & Kadin & 90 & 22,85 & \multirow{4}{*}{ 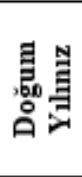 } & $1965-1979$ & 38 & 9,64 \\
\hline & Erkek & 304 & 77,15 & & $1980-1999$ & 356 & 90,36 \\
\hline & Toplam & 394 & 100 & & & & \\
\hline & & & & & Toplam & 394 & 100 \\
\hline \multirow{6}{*}{ 录 } & 1500 TL'den az & 242 & 61,4 & & & & \\
\hline & $\begin{array}{l}1500-3000 \mathrm{TL} \\
\text { aras1 }\end{array}$ & 65 & 16,5 & & & & \\
\hline & $\begin{array}{l}3000-4500 \mathrm{TL} \\
\operatorname{aras1}\end{array}$ & 41 & 10,4 & & & & \\
\hline & $\begin{array}{l}4500-6000 \mathrm{TL} \\
\text { aras1 }\end{array}$ & 28 & 7,1 & & & & \\
\hline & $\begin{array}{l}6000 \text { TL'den } \\
\text { yüksek }\end{array}$ & 18 & 4,6 & & & & \\
\hline & Toplam & 394 & 100 & & & & \\
\hline
\end{tabular}

\subsubsection{Araştırmanın Güvenirlilik ve Geçerlilik Analizi}

Hipotezler test edilmeden önce her ölçek grubuna Cronbach Alpha güvenilirlik analizi uygulanmıştır. Güvenilirlik analizi testi, anket ve ölçek gibi ölçme unsurlarının güvenilirlik seviyelerini saptamak amacıyla kullanılmaktadır (Kalaycı, 2006: 403). 0 ve 1 aralığında değerler alan Cronbach Alfa testinin sonuçları aşağıdaki skalaya göre yorumlanmaktadır (Özdamar, 2002: 673):

$$
\begin{aligned}
& 0,00<=\mathrm{x}<0,40 \text { "Güvenilir Değil" } \\
& 0,40<=\mathrm{x}<0,60 \text { "Düşük Güvenilirlik" } \\
& 0,60<=\mathrm{x}<0,80 \text { "Oldukça Güvenilir" } \\
& 0,80<=\mathrm{x}<1,00 \text { "Yüksek Güvenilirlik" }
\end{aligned}
$$

Araştırmada nomofobi ve çevrimiçi alışveriş bağımlılı̆̆ ölçeği olmak üzere iki ölçek kullanılmıştır. Söz konusu ölçeklerin güvenilirlik analizinde Cronbach's Alpha katsayısı, geçerlilik analizinde kullanılmış olup özeti Tablo 3 ve Tablo 4'te gösterilmiştir. Tablo 3'e göre; Nomofobi Ölçeği'ne ilişkin sorulardan oluşan ölçeğin genelinin Cronbach Alfa Katsayıs1 0,876 olarak saptanmıştır. Bu sonucu nomofobi ölçeğinin güvenilirliği \%87,6 olarak ifade etmek mümkündür. Buna göre Nomofobi Ölçeği Alfa katsayısına göre 'Yüksek Güvenilirlik' düzeyinde olduğu ifade edilebilir.

Tablo 3. Nomofobi Ölçeğinin Güvenilirlik-Geçerlilik Analizi

\begin{tabular}{|lc|}
\hline Nomofobi Ölçeği & $\%$ \\
\hline Ölçeğin tamamuna ilişkin Cronbach's Alpha &, 876 \\
\hline Ölçeğe ilişskin toplam açılanan varyans (\%) & 59,77 \\
\hline
\end{tabular}

Tablo 3'e göre, Nomofobi ölçeğinin varyansı ölçeğin bütününün \%59,77'lik bölümünü açıklayabilmektedir. Online Alışveriş Bağımlılığı Ölçeğinin güvenilirlik düzeyleri Tablo 4'te gösterilmiştir. Tablo 4'e göre, Online Alışveriş Bağımlılığı Ölçeğinin Alfa katsayısı 0,926 olarak tespit edilmiştir. Buna göre ölçeğin güvenilirlik düzeyi 'Yüksek Güvenilir' olarak tespit edilmiştir. İlgili ölçeğin varyans1 toplam ölçeğin \%68,01'lik bölümünü açıllama gücüne sahiptir. 
Tablo 4. Online Alışveriş Bağımlılı̆̆g Ölçeğinin Güvenilirlik-Geçerlilik Analizi

\begin{tabular}{|lc|}
\hline Online Alş̧veriş Bağımlilığı Ölçeği & $\%$ \\
\hline Ölçeğin tamamina ilişkin Cronbach's Alpha &, 926 \\
\hline Ölçeğe ilişkin toplam açlklanan varyans (\%) & 68,01 \\
\hline
\end{tabular}

Buna göre her iki ölçek için de güvenilirlik düzeylerinin sırasıyla \%87,6 ve \%92,6 olarak tespit edilmiş ve her iki ölçek de güvenilirlik açısından yüksek güvenilir olarak tespit edilmiştir.

\subsection{Nomofobi ve Çevrimiçi Alışveriş Arasındaki İlişki}

Bu çalışmanın amacı, $\mathrm{X}$ ve $\mathrm{Y}$ kuşağı tüketicilerin nomofobik eğilimlerinin çevrimiçi satın alma bağımlılığı ile olan ilişkisini belirlemeye yöneliktir. Bu kapsamda çalışmanın kavramsal modeli çerçevesinde üç ana hipotez geliştirilmiştir. İlk hipotez " $\mathrm{H}_{1}: \mathrm{X}$ ve $\mathrm{Y}$ kuşağı tüketiciler ile nomofobik eğilim düzeyleri arasında fark vardır." Hipotezi Anova (Tek Yönlü Varyans Analizi) yöntemi kullanılarak test edilmiştir. Bu kapsamda Anova Testinin uygulanabilmesi için ilk olarak varyansların homojen olup olmadığına bakılacaktır.

Tablo 5'te görüleceği üzere Homogenity of Varience Sig. Değeri 0,00 olarak tespit edilmiş ve varyansın homojen olmadığı sonucuna ulaşılmıştır. Bu bağlamda Anova testinin yapılabilmesi için ön koşulun sağlanmadığı ifade edilebilecektir. Ancak, varyansın homojenliği varsayımının ihlal edilmesi durumunda Brown-Forsythe veya Welch's F istatistikleri kullanılabilmektedir. BrownForsythe istatistiği grup varyanslarını ağırlıklandırarak varyansların homojen olmama durumlarını kontrol etmekte ve düzeltmeye çalışmaktadır. Bu istatistik büyük varyansa sahip örneklemlerin etkisini azaltarak Tip I hatayı kontrol altında tutmayı amaçlamaktadır. Bu iki istatistik arasında daha güçlü olan Welch test istatistiğidir (Şen, 2016). Bu nedenle bu hipotezde Welch istatistiğine bakılmıştır.

Tablo 5. $\mathrm{H}_{1}$ Hipotezi Varyansların Homojenliği Testi

\begin{tabular}{|c|c|c|c|c|}
\hline Kuşaklar ( X, Y) & $\begin{array}{c}\text { Levene } \\
\text { Statistics }\end{array}$ & df1 & df2 & Sig \\
\hline Homogenity of Variences & & & \multirow[b]{2}{*}{390} & \multirow[b]{2}{*}{$\mathbf{0 , 0 0}$} \\
\hline (Varyansların Homojenliği) & 17,120 & 3 & & \\
\hline
\end{tabular}

Tablo 6. $\mathrm{H}_{1}$ Hipotezi Varyansların Homojenliği Testi Welch's F İstatistiği

\begin{tabular}{|lcccc|}
\hline Kuşaklar (X, Y) & Statistics & df1 & df2 & Sig \\
\cline { 1 - 2 } & & & & \\
\cline { 1 - 2 } Homogenity of Variences & 960 & 3 & $\mathbf{2 1 . 9 0 7}$ & $\mathbf{0 , 4 2 2}$ \\
\hline
\end{tabular}

Tablo 6'da gösterilen Welch F istatistiği sonuçlarına göre; varyansların homojenliği varsayımını karşılamasa da testin uygulanabileceğini göstermektedir. $\mathrm{H}_{1}$ hipotezi Anova Testi özet olarak Tablo 7'de verilmiştir.

Tablo 7. $\mathrm{H}_{1}$ Anova Testi Sonuçları

\begin{tabular}{|c|c|c|c|c|c|c|}
\hline $\mathrm{H}_{1}$ & $\begin{array}{l}\text { Kareler } \\
\text { Toplamı }\end{array}$ & df & $\begin{array}{c}\text { Ortalama } \\
\text { Kareler }\end{array}$ & $\mathbf{F}$ & Sig & Sonuç \\
\hline Gruplar Arası & 1,025 & 3 &, 342 & \multirow{3}{*}{4,002} & \multirow{3}{*}{,008 } & \multirow{3}{*}{ KABUL } \\
\hline Grup İçi & 33,310 & 390 & 085 & & & \\
\hline Toplam & 34,335 & 393 & & & & \\
\hline
\end{tabular}


" $\mathrm{H}_{1}$ : X ve $\mathrm{Y}$ kuşağ tüketiciler ile nomofobik eğilim düzeyleri arasında fark vardır." hipotezi; $.008<0.05$ varsayımına istinaden kabul edilmiştir. Yani $\mathrm{X}$ ve $\mathrm{Y}$ kuşağı tüketiciler ile nomofobik eğilim düzeyleri arasında 1 serbestlik derecesi ve $\% 95$ güven aralığında anlamlı farklılık olduğu ifade edilebilecektir. X kuşağının ortalamas 2.305 iken Y kuşağını oluşturan katılımcıların ortalaması ise 2.540 olarak tespit edilmiştir. Buna göre $\mathrm{Y}$ kuşağı katılımcıların nomofobik eğilim düzeylerinin $\mathrm{X}$ kuşağına oranla daha yüksek olduğu yorumu yapılabilecektir.

\section{$\mathrm{H}_{2}$ 'nin Test Edilmesi:}

" $\mathrm{H}_{2}$ : X ve $\mathrm{Y}$ kuşağı tüketicilerin nomofobik eğilimleri ile çevrimiçi alışveriş bağımlılığı arasında ilişki vardır." Hipotezi MANOVA (Multivariate Analysis of Varience) - Çok değişkenli Varyans Analizi kullanılarak test edilmiştir. Grup sayısı en az iki olan bir bağımsız değişken ile birden çok sayıda bağımlı değişkenin arasındaki bağlantının test edilmesi durumunda kullanılan istatistiksel metot MANOVA testidir (Ulusoy, 2018:178). Burada her iki bağımlı değişken ile bağımsız değişkenin ayrı ayrı varyans analizlerinin yapılması şeklinde de analiz yapılması mümkün olsa da Çok değişkenli varyans analizi daha etkili bir test olarak ifade edilebilecek (Kanık, 1999: 23) ve tek tek test edilmesi Tip I hata miktarın artırabilecektir (Ulusoy, 2018: 179).

Tablo 8. $\mathrm{H}_{2}$ Hipotezi Kovaryans Matrislerinin Eşitliği Testi (Box's Test)

\begin{tabular}{|c|c|c|c|c|c|c|}
\hline $\mathbf{H}_{2}$ & Box's M & & $\mathbf{F}$ & df1 & df2 & Sig. \\
\hline Box's Test of & & & & & & \\
\hline Covarience Matrices & 682,110 & 394 & 2,672 & 234 & 15,704 & ,000 \\
\hline
\end{tabular}

Manova testinin özet tablosu incelenirken, ilk olarak Box’s Test sonucu incelenmektedir. Eğer kovaryans matrislerinin homojenliği varsayımı elde ediliyorsa Wilk's Lambda; varyansların homojenliği varsayımının ihlali vaziyetinde Pillai's Trace istatistiği kullanılır (Mertler ve Reinhart, 2005: 126). Pillai's Trace istatistiğinin çok değişkenli varyans analizinde ön şartların sağlanmadığı, bilhassa kovaryans matrislerinin heterojen olduğu durumlarda öteki seçeneklerinegöre daha güçlüdür (Carey, 1998).

Tablo 9. $\mathrm{H}_{2}$ Hipotezi Manova Testi Sonuçları

\begin{tabular}{|c|c|c|c|c|c|c|}
\hline $\mathrm{H}_{2}$ : MANOVA Testi (S2*NomTan) & Value & $\mathbf{f}$ & Df & $\begin{array}{c}\text { Error } \\
\text { df }\end{array}$ & Sig. & Sonuç \\
\hline Pillai's Trace & 0,82 & $1,860^{\mathrm{b}}$ & 18,00 & \multirow{3}{*}{374,00} & \multirow{4}{*}{, 074} & \multirow{4}{*}{ RED } \\
\hline Wilks' Lambda & ,918 & $1,860^{\mathrm{b}}$ & 18,00 & & & \\
\hline Hotelling's Trace &, 090 & $1,860^{\mathrm{b}}$ & 18,00 & & & \\
\hline Royce's Largest Root &, 090 & $1,860^{\mathrm{b}}$ & 18,00 & & & \\
\hline
\end{tabular}

Tablo 9'a göre, Pillai's Trace istatistiği 0,074 olarak tespit edilmiştir. 0,074>0,05 olduğu için " $\mathrm{H}_{2}$ : $\mathrm{X}$ ve $\mathrm{Y}$ kuşağı tüketicilerin nomofobik eğilimleri ile çevrimiçi alışveriş bağımlılığı arasında ilişki vardır." Hipotezi \%95 güven aralığı, 1 serbestlik derecesinde reddedilmiştir.

\section{$\mathrm{H}_{3}$ Hipotezinin Test Edilmesi}

" $\mathrm{H}_{3}$ : X ve Y kuşağı tüketicilerin cinsiyetleri ile nomofobik eğilim seviyeleri arasında ilişki vardır." Hipotezi Manova Testi ile test edilmiştir. Tablo 10'da Kovaryans Matrislerinin Eşitliği sonuçları verilmiştir. 


\begin{tabular}{|c|c|c|c|c|c|}
\hline \multicolumn{6}{|c|}{ Tablo 10. $\mathrm{H}_{3}$ Hipotezi Kovaryans Matrislerinin Eșitliği Testi (Box's Test) } \\
\hline $\mathbf{H}_{3}$ & Box's M & $\mathbf{F}$ & df1 & df2 & Sig. \\
\hline Box's Test of & & & & & \\
\hline Covarience Matrices & 726,385 & 2,003 & 312 & $\mathbf{3 5 , 2 3 4}$ &, 000 \\
\hline
\end{tabular}

Tablo 11. $\mathrm{H}_{3}$ Hipotezi Manova Testi Sonuçları

\begin{tabular}{|c|c|c|c|c|c|c|}
\hline H3: MANOVA Testi (S1*NomTan) & Value & f & Df & $\begin{array}{c}\text { Error } \\
\text { df }\end{array}$ & Sig. & Sonuç \\
\hline Pillai's Trace & ,005 & $1,014^{b}$ & 2,00 & \multirow{4}{*}{391.00} & \multirow{4}{*}{,364 } & \multirow{4}{*}{ RED } \\
\hline Wilks' Lambda & ,995 & $1,014^{\mathrm{b}}$ & 2,00 & & & \\
\hline Hotelling's Trace &, 005 & $1,014^{\mathrm{b}}$ & 2,00 & & & \\
\hline Royce's Largest Root & 005 & $1,014^{\mathrm{b}}$ & 2,00 & & & \\
\hline
\end{tabular}

Tablo 11'e göre, Pillai's Trace istatistiği 0,002 olarak tespit edilmiştir. 0,364>0,05 olduğu için " $\mathrm{H}_{3}: \mathrm{X}$ ve $\mathrm{Y}$ kuşağı tüketicilerin cinsiyetleri ile nomofobik eğilim düzeyleri arasında ilişki vardır." hipotezi \%95 güven aralığı, 1 serbestlik derecesinde reddedilmiştir.

\section{Sonuç ve Öneriler}

$\mathrm{X}$ ve $\mathrm{Y}$ kuşağı tüketicilerin nomofobik eğilimleri (Cep telefonsuz kalma korkuları) ile çevrimiçi alışveriş bağımlılıkları arasında ilişkiyi belirlemeyi amaçlayan bu çalışma kapsamında üç ana hipotez geliştirilmiştir. Bu kapsamda istatistiksel analiz metodları ile test edilen bu üç hipotezde sırasıyla; " $\mathrm{H}_{1}$ : X ve Y kuşağı tüketiciler ile nomofobik eğilim düzeyleri arasında fark vardır." Hipotezi, KABUL; " $\mathrm{H}_{2}: \mathrm{X}$ ve $\mathrm{Y}$ kuşağı tüketicilerin nomofobik eğilimleri ile çevrimiçi alışveriş bağımlılığ 1 arasında ilişki vardır." Hipotezi, RED ve "H $\mathrm{H}_{3}$ X ve Y kuşağ tüketicilerin cinsiyetleri ile nomofobik eğilim düzeyleri arasında ilişki vardır." Hipotezi, RED olarak belirlenmiştir.

Çalışmadan elde edilen sonuçlara göre kuşaklar ve nomofobik eğilimler arasında anlamlı ilişki tespit edilmiş; kuşaklar ve çevrimiçi alışveriş bağımlılıkları arasında anlamlı bir bağlantı saptanamamış ve son olarak kuşaklara göre cinsiyetler ve çevrimiçi alışveriş bağımlılıkları arasında anlamlı bir ilişski bulunamamıştır. Kabul sonuçlarına bakıldığında Y kuşağı frekansının yüksek olmasını ve üçüncü hipotezde ise kadın katılımcıların sayısının az olmasının etkili olacağı ifade edilebilecektir.

İncelenmiş olan literatür çalışmalarında genel olarak bireylerin çoğunda nomofobik eğilimlerin yüksek olduğu sonucuna varılmıştır. Yapılan araştırmalarda, Nomofobi ile ilişkilendirilmiş olan kavramlar neticesinde bireylerin cep telefonundan ayrı kalmaları söz konusu olamamaktadır. Yapılan çalışmalar daha çok eğitim bilimleri ile ilgili olmasından dolayı, bu çalışma literatüre kuşaklar bazında incelenmesi açısından özgün değer olma niteliği taşımaktadır.

Bundan sonra yapılacak çalışmalarda Z kuşağı ya da eğitim düzeyleri ile nomofobi kavramı arasındaki ilişki incelenebilir.

\section{Kaynakça}

Akman, E., ve Iş1k, M. (2018). Kamu çalışanlarında internetsiz kalma korkusu (netlessfobi): ısparta ilinde bir araştırma, Avrasya Uluslararası Araştırmalar Dergisi, 6(14), 20-37. https://dergipark.org.tr/tr/download/article-file/622552. https://doi.org/10.33692/avrasyad.510600

Akyüz, M.C. (2017). Taraftarların Çevrimiçi Alışverişe Karşı Tutumlarının İncelenmesi: Süper Lig Futbol Kulüp Taraftarlarl Üzerine Bir Araştırma. (Yüksek lisans tezi). Marmara Üniversitesi Sağllk Bilimleri Enstitüsü, İstanbul. http://hdl.handle.net/11424/36711 
Alt, D. (2015). College students' academic motivation, media engagement and fear of missing out, Computers in Human Behavior, 49: 111-119. https://doi.org/10.1016/j.chb.2015.02.057

Alternatif Bank (2020, 19 Ocak). Sessiz Kuşak - Baby Boomers - X - Y - Z kuşaklarına genel bakış. https://alternatifbankkariyer.com/2014/07/17/sessiz-kusak-baby-boomers-X-y-Zkusaklarina-genel-bakis/

Başgöze, P., \& Bayar, N. A. (2015). Eko otellerden hizmet satın alımında kuşaklar arası farklılaşmalar üzerine bir çalışma. Sosyoekonomi, 23(2), https://doi.org/10.17233/se.40582.

Başlama, M.C. (2008). İnternette Reklamlar ve E-Alışveriş İlişkisi: İnternet Kullanıcılarına Yönelik Bir Uygulama. (Yüksek Lisans Tezi). Ege Üniversitesi Sosyal Bilimler Enstitüsü, İzmir. https://doi.org/10.17218/hititsosbil.596267

Bozdağ, Y. \&Alkar, Ö. Y. (2018). Bergen alışveriş bağımlılığı ölçeği'nin kompülsif çevrimiçi satın alma davranışına uyarlanması. Bağımlılık Dergisi, 19(2), 23-34.

Carey, G. (1998). Multivariate Analysis Of Variance (MANOVA), Theory I, Colorado: y.e.y., http://ibgwww.colorado.edu/ carey/p7291dir/handouts/manova1.pdf.

Danışman, A. Ş., \& Gündüz, Ş. (2018). X ve Y kuşaklarının dışarıdan kahvaltı satın alma davranış farklılıkları. Atatürk Üniversitesi Sosyal Bilimler Enstitüsü Dergisi, 707-728. https://doi.org/10.29029/busbed.381903

Demirkaya, H., Akdemir, A., Karaman, E., \& Atan, Ö. (2015). Kuşakların yönetim politikas1 beklentilerinin araştırılması. İşletme Araştırmaları Dergisi, 7(1), 186-204.

Enginkaya, E. (2006). Elektronik perakendecilik elektronik alışveriş. Ege Akademik Bakış Dergisi, 6(1), 10-16.

Erdem, H., Kalkın, G., Türen, U. ve Deniz, M. (2016). Üniversite öğrencilerinde mobil telefon yoksunluğu korkusunun (nomofobi) akademik başarıya etkisi. Süleyman Demirel Üniversitesi Iktisadi ve İdari Bilimler Fakültesi Dergisi, 21 (3) :923-936. https://doi.org/10.17556/erziefd.512074

Ersoy, E. (2016). Tületicilerin değişen alışveriş alışkanlıklarl: Online alışveriş. (Yüksek Lisans Tezi) İstanbul Aydın Üniversitesi Sosyal Bilimler Enstitüsü, İstanbul. http://91.239.204.115/bitstream/11547/2163/1/454534.pdf

Ertan, G. (2019). Mobil Telefonsuz Kalma Korkusunun (Nomofobi) İş Tatmini, İle Bă̆lllık Ve Sosyal İzolasyon Üzerine Etkisi. (Yüksek lisans tezi.). Marmara Üniversitesi, Sosyal Bilimler Enstitüsü, İstanbul. https://doi.org/10.33905/bseusbed.474469

Gençtan, E. (2015). Psikodinamik psikiyatri ve normal dışı davranışlar. İstanbul: Metis Yayınları.

Gezgin, D. M. (2017). Exploring The Influence Of The Patterns Of Mobile Internet Use On University Students'nomophobia Levels. European Journal of Education Studies, 3(6), 29 53. http://dx.doi.org/10.5281/zenodo.572344.

Güney, B. (2017). Dijital bağımlılı̆̆ın dijital kültüre dönüşmesi: Netlessfobi”, Yeni Medya Elektronik Dergisi, 1(2), 207-213. https://doi.org/10.17932/iau.ejnm.25480200.2017.1/2.207-213

Işık, M. ve Kaptangil, İ. (2018). Akıllı telefon bağımlılığının sosyal medya kullanımı ve beş faktör kişilik özelliği ile ilişkisi: Üniversite öğrencileri üzerinden bir araştırma. İnsan Ve Toplum Bilimleri Araştırmaları Dergisi, 7 (2): 695-717. https://doi.org/10.15869/itobiad.361081

Kalaycı, Ş.(2006). SPSS uygulamalı çok değişkenli istatistik teknikleri. Ankara: Asil Yayın Dağıtım. 
Kanık, A. E. (1999). Çok Değişkenli Varyans Analizinde KovaryansMatrislerinin Homojenliği Ön Şartı (Doktora tezi). Ankara Üniversitesi Fen Bilimleri Enstitüsü, Ankara. http://acikarsiv.ankara.edu.tr/browse/26114/

Karatay, S. (2018). Hyperconnectivity Kavramı Bağlamında Mobil Sosyal Medya Uygulamaları: Nomofobi Ve Fomo Rahatsızlıklarına Yönelik Bir Araştırma. (Yüksek lisans tezi). İstanbul Üniversitesi, Sosyal Bilimler Enstitüsü, İstanbul. https://doi.org/10.12780/uusbd.84581

Kurnia, S., \& Chien, J. A. W. (2003). The acceptance of the online grocery shopping. In The 16th Bled Electronic Commerce Conference, Bled, Slovenia.

Lepp, A., Li, J., \&Barkley, J. E. (2016). Collegestudents' cell phone use and attachment to parents and peers. Computers in Human Behavior, 64, 401-408. https://doi.org/10.1016/j.chb.2016.07.021

Li, N., \& Zhang, P. (2002). Consumer online shopping attitudes and behavior: An assessment of research. AMCIS 2002 Proceedings, 74.

Mercan, N. (2016). X, Y ve Z kuşağı kadınların farklı tüketim alışkanlarının modern dünyada inşa edilmesi. Kadem Kadın Araştırmalart Dergisi, 2(1), 59-70, https://doi.org/10.21798/kadem.2016119797

Mertler, C. A., \& Reinhart, R. V. (2015). Advanced and multivariate statistical methods: Practical application and interpretation. Routledge.

Mücevher, M. H. (2015). X Ve Y Kuşağının Birbirlerine Karşı Özellik Ve Etkileşim Algıları: SDÜ Örneği (Yüksek Lisans Tezi). Süleyman Demirel Üniversitesi Sosyal Bilimler Enstitüsü, Isparta. https://doi.org/10.21076/vizyoner.391745

Ordun, G. (2015). Millennial (Gen Y) consumer behavior their shopping preferences and perceptual maps associated with brand loyalty. Canadian Social Science, 11(4), 40-55.

Öz, H. (2018). Üniversite Okuyan Genç Yetişkinlerin Mobil Telefon Yoksunluğu Korkusu (Nomofobi) Ile Kişilik Tipleri Arasındaki İlişkinin Incelenmesi. (Yüksek lisans tezi). İstanbul Aydın Üniversitesi, Sosyal Bilimler Enstitüsü, İstanbul. https://doi.org/10.34087/cbusbed.600130

Özdamar, K. (2002). Paket programlar ile istatistiksel veri analizi. Eskişehir: Kaan Kitabevi.

Öztürk, U. C. (2015). Bağlantıda kalmak ya da kalmamak işte tüm korku bu: İnternetsiz kalma korkusu ve örgütsel yansımaları. Journal of International Social Research, 8(37). https://doi.org/10.17719/jisr.20153710629

Scientific American (2015, 27 Ekim). Scientistsstudynomophobia: fear of beingwithout a mobile phone, scientificamerican. https://www.scientificamerican.com/article/scientists- studynomophobia-mdash-fear-of-being-without-a- mobile-phone/.

Sırakaya, M. (2018). Ön lisans öğrencilerinin nomofobi düzeylerinin akıllı telefon kullanım durumlarına göre incelenmesi. Mersin Üniversitesi Eğitim Fakültesi Dergisi, 14(2), 714727, https://doi.org/10.17860/mersinefd.359458

Song, X., Zhang, X., Zhao, Y., \& Song, S. (2017). Fearing of missing out (fomo) in mobil social media environment: conceptual development and measurement scale, In iConferenre 2017 Proceedings: 733-738.

Şen, S. (2016). SPSS ile 2'den fazla grup karşılaştırması (Anova). https://sedatsen.files.wordpress.com/2016/11/3-sunum.pdf adresinden erişildi. 
Tavolacci, M. P., Meyrignac, G., Richard, L., Dechelotte, P., \&Ladner, J. (2015).Problematicuse of mobile phoneandnomophobiaamong French collegestudents. The EuropeanJournal of Public Health, 25(3), 206. https://doi.org/10.1093/eurpub/ckv172.088

Türen, U., Erdem, H., Kalkın, G. (2017). Mobil telefon yoksunluğu korkusu (nomofobi) yayılımı: Türkiye'den üniversite öğrencileri ve kamu çalışanları örneklemi. Bilişim Teknolojileri Dergisi, 10(1), 1. https://doi.org/ 10.17671/btd.30223

Türk Dil Kurumu. Fobi. Türk Dil Kurumu Sözlük. 6 Ekim 2019'da https://sozluk.gov.tr/ adresinden alınd1. https://doi.org/10.29000/rumelide. 133740

Türk Dil Kurumu. Kuşak. Türk Dil Kurumu Sözlük. 19 Ocak 2020'de https://sozluk.gov.tr/?kelime=ku\%C5\%9Fak adresinden alınd1. https://doi.org/10.29000/rumelide.133740

Türkiye İstatistik Kurumu. (2019, 6 Ekim). Hanehalkı bilişim teknolojileri. http://www.tuik.gov.tr/PreHaberBultenleri.do?id=27819

Türkiye İstatistik Kurumu. (2019, 6 Ekim). Hanehalkı bilişim teknolojileri. http://www.tuik.gov.tr/PreHaberBultenleri.do?id=30574

Ulusoy, G. (2018). Gıda Perakendeciliği Sektöründe Tüketicilerin Yeniden Satın Alma Kararları Üzerinde Mă̆aza Atmosferi Unsurlarının Etki Düzeyi Farklılıklarının Belirlenmesi: EEG ve Göz İzleme Yöntemlerine Dayall Deneysel Bir Araştırma. (Yüksek lisans tezi). , Hitit Üniversitesi SBE, Çorum. https://doi.org/10.29029/busbed.381903

Yaman, B., Geçgil, G., \& Yavuz, G. (2018). Elektronik ticaret ve mobil ticaret üzerine bir inceleme: meta-analiz çalışması. R\&S-Research Studies Anatolia Journal, 1(2), 142-153. https://doi.org/10.33723/rs.428407

Yıldırım, S., \& Kişioğlu, A. N. (2018). Teknolojinin getirdiği yeni hastalıklar: Nomofobi, netlessfobi, fomo. SD $\ddot{U}$ Tip Fakültesi Dergisi, 25(4), 473-480, https://doi.org/10.17343/sdutfd.380640

Y1lmaz, A., \& Uzunçelebi, H. (2015). Modern tüketim kültüründen postmodern tüketim kültürüne geçişin elektronik ticaret üzerinde oluşturduğu etkiler. Atatürk Illetişim Dergisi, (9), 13-34.

Yildirim, C., \& Correia, A. P. (2015). Exploring the dimensions of nomophobia: Development and validation of a self-reported questionnaire. Computers in Human Behavior, 49, 130-137. https://doi.org/10.1016/j.chb.2015.02.059

Yildirim, C., Sumuer, E., Adnan, M., \&Yildirim, S. (2016). A growingfear: Prevalence of nomophobia among Turkish college students. Information Development,32(5), 1322-1331. https://doi.org/10.1177/0266666915599025

Yörükoğlu, A. (1990). Gençlik çă̆ı. İstanbul: Özgür Yayın Dağıtım.

Yüksekbilgili, Z. (2013). Türk tipi Y kuşağı. Elektronik Sosyal Bilimler Dergisi, 12(45), 342-353. 